\title{
Identification of NR0B1 as a novel androgen receptor co-repressor in mouse Sertoli cells
}

\author{
YU-CHI LI ${ }^{1,2^{*}}$, MAN-LING LUO ${ }^{1,2^{*}}$, HUAN GUO $^{1,3^{*}}$, TIAN-TIAN WANG $^{1}$, SHOU-REN LIN $^{1}$, \\ JIAN-BO CHEN ${ }^{1,4}$, QIAN MA ${ }^{1}$, YAN-LI GU ${ }^{1}$, ZHI-MAO JIANG ${ }^{1}$ and YAO-TING GUI ${ }^{1}$ \\ ${ }^{1}$ Guangdong and Shenzhen Key Laboratory of Male Reproductive Medicine and Genetics, Institute of Urology, \\ Peking University Shenzhen Hospital, Shenzhen PKU-HKUST Medical Center, Shenzhen, Guangdong 518036; \\ ${ }^{2}$ Shantou University Medical College, Shantou, Guangdong 515041; ${ }^{3}$ Guangzhou Medical University, \\ Guangzhou, Guangdong 510182; ${ }^{4}$ Anhui Medical University, Hefei, Anhui 230032, P.R. China
}

Received May 30, 2015; Accepted June 22, 2016

DOI: $10.3892 /$ ijmm.2016.2672

\begin{abstract}
Nuclear receptor subfamily 0 group B member 1 $(\mathrm{NrObl})$ is an atypical member of the nuclear receptor family that is predominantly expressed in mouse Sertoli cells (SCs). Mutations of NROB1 in humans cause adrenal failure and hypogonadotropic hypogonadism. The targeted mutagenesis of $\mathrm{NrObl}$ in mice has revealed a primary gonadal defect characterized by the overexpression of aromatase and cellular obstruction of the seminiferous tubules and efferent ductules, leading to germ cell death and infertility. The transgenic expression of $\mathrm{NrObl}$ under the control of the Müllerian-inhibiting substance promoter (MIS-NrOb1), which is selectively expressed in SCs, improves fertility. Testicular androgen receptor (AR) was also expressed in SCs. Many genes are directly regulated by androgen and its AR, which are involved in spermatogenesis and male infertility. As the association between NR0B1 and AR remains unclear in mouse SCs, we decided to further explore the relationship between them. In the present study, we have identified NR0B1 as a novel AR co-repressor in mouse SCs. Using RT-qPCR and immunofluorescence, we determined that NR0B1 was mainly expressed in mouse SCs in an age-dependent manner from 2-8 weeks of age postnatally. The inhibition of the effects of AR on AR target genes by NR0B1, in an androgen-dependent manner, was further demonstrated by western blot analysis and RT-qPCR in TM4 cells, a mouse Sertoli cell line. Finally, in vitro luciferase and co-immunoprecipitation assays validated that NR0B1, as an AR co-repressor, significantly inhibited the transcriptional activation of its target genes. These results
\end{abstract}

Correspondence to: Dr Yao-Ting Gui, Guangdong and Shenzhen Key Laboratory of Male Reproductive Medicine and Genetics, Institute of Urology, Peking University Shenzhen Hospital, Shenzhen PKU-HKUST Medical Center, 1120 Lianhua Road, Shenzhen, Guangdong 518036, P.R. China

E-mail: guiyaoting2007@aliyun.com

*Contributed equally

Key words: NR0B1, Sertoli cells, androgen receptor, co-repressor, transcription suggest that novel inhibitory mechanisms underlie the effects of NR0B1 in modulating androgen-dependent gene transcription in mouse SCs.

\section{Introduction}

Nuclear receptor subfamily 0 group B member 1 (NrObl) is an orphan nuclear receptor expressed in the ventromedial hypothalamus, pituitary gonadotropes, the adrenal cortex, the testis and the ovary $(1,2)$. The duplication of a region of the $\mathrm{X}$-chromosome spanning NROB1 results in dosage sensitive, male-to-female sex reversal (3). Mutations of NROBl cause an $\mathrm{X}$-linked form of adrenal hypoplasia congenita in males, who usually present with an adrenal crisis during the first year of life (4). The disorder is limited to males and is characterized by neonatal adrenal insufficiency and failure to undergo puberty as a result of hypogonadotropic hypogonadism. It has been demonstrated that the targeted disruption of $\mathrm{NrObl}$ in male mice results in infertility, decreased testicular size, and degeneration of germinal epithelium (5). A thorough histological examination of the male reproductive tract from $\mathrm{NrObl}$ knockout ( $\mathrm{NrObl-KO}$ ) mice revealed that the rete testis, the passageway for sperm to leave the testis, is obstructed by ectopic clusters of Sertoli cells (SCs) (6). Despite these findings, the function of $\mathrm{NrObl}$ in the male reproductive system remains unclear.

Androgen and its receptor, androgen receptor (AR), play important roles in spermatogenesis and male fertility (7-9). The AR belongs to a family of nuclear transcription factors that mediate the action of androgens. It contains an N-terminal transactivation domain, a central DNA-binding domain (DBD), and a C-terminal ligand-binding domain (LBD). Cytoplasmic $\mathrm{AR}$, when bound by androgens, translocates to the nucleus and binds to the androgen response elements (AREs) on target genes. Testicular AR has been detected in Leydig cells, peritubular cells and SCs (10). Androgens affect spermatogenesis indirectly through AR-expressing somatic cells, such as SCs or peritubular myoid cells (10). AR mutations cause a spectrum of hereditary disorders, including androgen insensitivity syndrome and male infertility (11). Furthermore, male total AR-KO mice exhibited a typical female external appearance, which was similar to a human 
androgen-insensitivity syndrome or testicular feminization mutation in mice (12).

In light of accumulating data regarding the function and expression of NR0B1, we became interested in studying the possible interactions between NR0B1 and AR. The AR is a member of the steroid hormone receptor branch of the nuclear receptor superfamily and, as a mediator of androgen signaling, it plays important roles in coordinating gene expression in male reproductive tissues (13-16). A number of distinct co-regulatory factors are involved in the regulation of AR signaling (17). Although many of these factors function as bona fide co-activators or co-repressors by directly communicating with chromatin and the transcription machinery, additional co-regulators may exist that function in an antagonistic manner by preventing, disrupting or redirecting interactions with bona fide co-activators and co-repressors.

In the present study, we have identified NR0B1 as an inhibitory co-regulator of AR. To the best of our knowledge, we have provided evidence of previously uncovered aspects of the mechanisms of action of NR0B1 in mouse SCs. The data strongly suggest that NR0B1 antagonism plays a physiological role in modulating AR-dependent gene regulation in male reproductive tissues.

\section{Materials and methods}

Reagents and medium. Rabbit polyclonal anti-NR0B1 antibody (ab60144), anti-AR antibody (ab74272) and mouse monoclonal anti-GAPDH antibody (ab8245) were purchased from Abcam (Cambridge, UK). Anti-HA antibody (H3663) was purchased from Sigma-Aldrich (St. Louis, MO, USA). Anti-SOX9 antibody was purchased from Millipore Corp. (Billerica, MA, USA). Anti-rabbit-Cy3, anti-rabbit-Alexa Fluor 488, anti-mouse-Cy3 and anti-mouse-Alexa Fluor 488 were purchased from Invitrogen (Carlsbad, CA, USA). All restriction endonucleases were purchased from New England BioLabs, Inc. (Ipswich, MA, USA). The Dual-Luciferase reporter assay system and the pGL4.15 plasmid, which was used to construct two recombinant plasmids [pUBE2B(-882/343)-LUC and pHSF1(-625/-390)-LUC], were obtained from Promega Corp. (Madison, WI, USA). Lipofectamine 2000 was obtained from Invitrogen.

Animals and tissue collection. One hundred mice (C57BL/6) were purchased from the Southern Medical University Animal Center (Guangzhou, China). All animals were treated according to the National Research Council Guide for the Care and Use of Laboratory Animals. The study was approved by the Ethics Committee of Peking University Shenzhen Hospital (Shenzhen, China).

The mouse testes were individually collected from the mice at 1, 2, 3, 4, 6 and 8 weeks, and 6 months of age after sacrifice by cervical dislocation. Five mice were sacrificed in each group at each time-point. Other organs, namely the brain, heart, lung, liver, kidney, spleen, epididymis and bladder, were obtained from adult mice at 8 weeks of age.

Reverse transcription-quantitative polymerase chain reaction $(R T-q P C R)$. Total RNA was extracted from mouse tissues and TM4 cells using TRIzol (Invitrogen) according to the manufacturer's instructions. First strand cDNA was synthesized using oligo(dT) primers (K1622; Fermentas, Waltham, MA, USA). The primers specific for mouse NrObl were 5'-CACAGAGCAGCCACAGATG-3' (forward), and 5'-AATG TTCAGACTCCAGCACTTG-3' (reverse). The primers for Ube2b were 5'-GCAGCTGCGGAGCATGTCGA-3' (forward), and 5'-CAGATGGGGCGCCACTGACC-3' (reverse); The Hsf1 primers were 5'-CTGGTCCGTGTCAAGCAA-3' (forward), and 5'-GGCTACGCTGAGGCACTT-3' (reverse). Mouse Gapdh was used as an internal control and the primers for Gapdh were 5'-AGTGGCAAAGTGGAGATT-3' (forward), and 5'-GTGG AGTCATACTGGAACA-3' (reverse). RT-qPCR was performed using the SYBR ${ }^{\circledR}$ Premix EX Taq ${ }^{\mathrm{TM}}$ II PCR kit (RR820A; Takara, Dalian, China) according to the manufacturer's instructions on the Roche LightCycler 480 Real-Time PCR system (Mannheim, Germany). The data were calculated according to the Applied Biosystems comparative $(\mathrm{Ct})$ method (18).

Western blot analysis. The proteins were extracted from mouse tissues and TM4 cells and separated by $10 \%$ sodium dodecyl sulfate-polyacrylamide gel electrophoresis (SDS-PAGE) and electrotransferred onto polyvinylidene fluoride (PVDF) membranes (Millipore Corp., Bedford, MA, USA). The membranes were blocked with $10 \%$ (w/v) low-fat milk in TBST (20 mM Tris- $\mathrm{HCl}$ pH 7.5, $150 \mathrm{mM} \mathrm{NaCl}, 0.1 \%$ Tween20). Following incubation with the anti-NR0B1 antibody (1:1,000; \#ab60144; Abcam), anti-UBE2B antibody $(1: 2,000$; \#10733-1-AP; Proteintech, Chicago, IL, USA) and anti-HSF1 antibody (1:2,000; \#ABE1044; Millipore Corp.) overnight at $4^{\circ} \mathrm{C}$, the membranes were treated with HRP-labeled secondary antibody (ab6721; Abcam) for $1 \mathrm{~h}$ at room temperature. Positive bands were detected using an ECL kit (Thermo Fisher Scientific, Waltham, MA, USA).

Immunofluorescence analysis. The mouse testes were fixed in Tissue-Tek (Sakura Finetek USA, Inc., Torrance, CA, USA) and sectioned with an ultra-thin semiautomatic microtome (CUT4062; Leica Microsystems, Bensheim, Germany). After being blocked in $10 \%$ goat serum, incubated with anti-NR0B1 polyclonal antibody (1:50), anti-AR antibody (1:50) and anti-SOX9 antibody $(1: 100)$ overnight at $4{ }^{\circ} \mathrm{C}$, the appropriate FITC- or TRITC-conjugated secondary antibodies were used, and the slides were counterstained with Hoechst 33258 and mounted with ProLong Gold antifade reagent (both from Invitrogen). Primary antibody pre-incubated with neutralizing peptide was used as a negative control. The results were observed under a laser scanning confocal microscope (Zeiss, Oberkochen, Germany) and analyzed using Image-Pro Plus 5.1 software.

Plasmid construction and cell culture. The full length of NrObl cDNA was amplified by PCR with the primers, 5'-CCG GAATTCATGGCGGGTGAGGACCACC-3' (forward), and 5'-CCGCTCGAGTCACAGCTTTGC ACAGAGCATCTCC-3' (reverse), and then inserted into pCDNA3.1/HA plasmids using EcoR1 and Xhol. The PCR products were cloned and sequenced. Three cell lines, TM4, 15P1 and 293T, were obtained from the American Type Culture Collection (ATCC; Manassas, VA, USA). The cells were maintained in Dulbecco's modified Eagle's medium (DMEM; Life Technologies, 
A

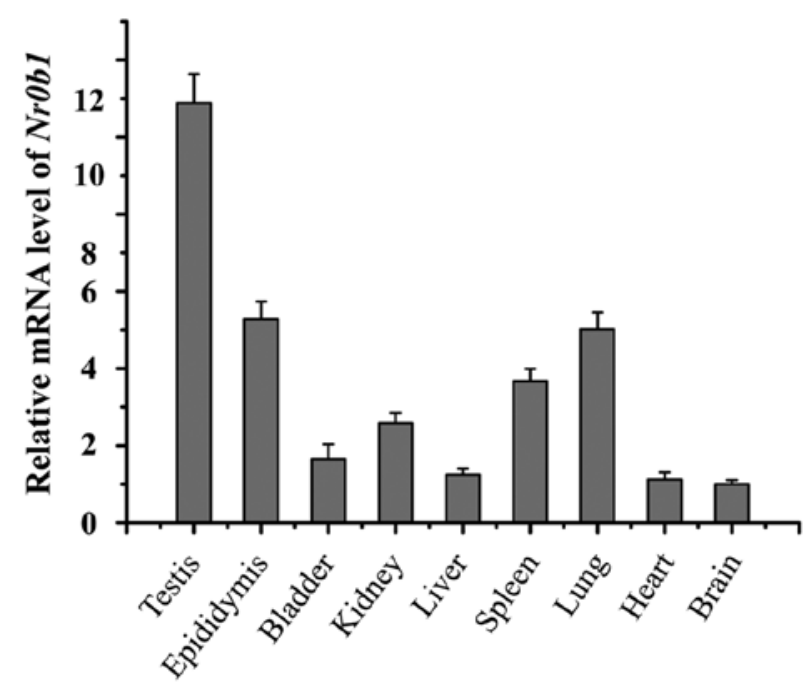

B

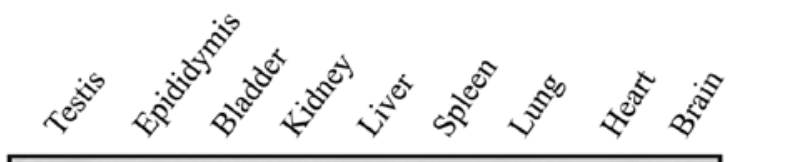

NR0B1, $52.5 \mathrm{kDa}$

GAPDH, $36 \mathrm{kDa}$

Figure 1. Analysis of the distribution of $\mathrm{NrOb1}$ mRNA and its protein in mouse tissues. (A) The mRNA expression of $\mathrm{NrOb1}$ in different tissues of adult mice was detected by RT-qPCR. After normalizing to Gapdh, the relative expression level of $\mathrm{NrOb1}$ in different tissues was compared with that in the brain. Data are expressed as the means $\pm \mathrm{SD}(\mathrm{n}=5)$. (B) The protein expression of NR0B1 was detected by western blot analysis. The molecular weight of each protein is shown on the right. GAPDH was used as an internal control. All experiments were performed three times by independent individuals.

Rockville, MD, USA) supplemented with $10 \%$ fetal bovine serum at $37^{\circ} \mathrm{C}$ in a humidified atmosphere with $5 \% \mathrm{CO}_{2}$.

RNA Interference. The siRNAs targeting mouse NrOb1 (siNr0b1, 5'-UAUCUGAAAGGGACCGUGCTCTT-3') were obtained from GenePharma Co., Ltd. (Shanghai, China). The TM4 cells were seeded in a 6-well plate and transfected with 200-pmol pools of siNrOb1 using Lipofectamine 2000 (Invitrogen) according to the manufacturer's instructions.

Co-immunoprecipitation (Co-IP). The cell cultures were prepared as described above. NR0B1-pCDNA3.1/HA was transfected into $293 \mathrm{~T}$ cells together with AR-pCDNA3.1 ${ }^{+}$or the vector control using Lipofectamine 2000 transfection reagent according to the manufacturer's instructions. The cells were harvested $48 \mathrm{~h}$ after transfection, washed with TBS (50 mM Tris- $\mathrm{HCl}(\mathrm{pH} 7.4)$ and $150 \mathrm{mM} \mathrm{NaCl}$ ), and then the cells were lysed on ice for $30 \mathrm{~min}$ with lysis buffer [50 mM Tris- $\mathrm{HCl}$ (pH 7.4), 2 mM EGTA or $\mathrm{CaCl}_{2}, 150 \mathrm{mM} \mathrm{NaCl}, 1 \%$ (v/v) NP-40, protease inhibitor cocktail (P8340; Sigma-Aldrich), and $1 \mathrm{mM}$ PMSF]. The lysates were centrifuged at $13,000 \mathrm{x}$ g for $15 \mathrm{~min}$ at $4^{\circ} \mathrm{C}$. The supernatants were incubated with nProtein A Sepharose 4 Fast Flow (GE Healthcare, Little Chalfont, UK) pre-bound with anti-HA or anti-AR antibody at $4{ }^{\circ} \mathrm{C}$ overnight with gentle rotation. The beads were washed four times with lysis buffer and prepared with SDS-PAGE sample buffer for western blot analysis.

Luciferase assay. Two mouse SC lines, TM4 (6x $10^{4}$ cells/well) and $15 \mathrm{P} 1\left(8 \times 10^{4}\right.$ cells/well), were seeded into a 24 -well plate and transfected with $200 \mathrm{ng}$ AR-pCDNA3.1, $200 \mathrm{ng}$ pMMTV-LUC or pUBE2B(-882/-343)-LUC or pHSF1(-625/-390)-LUC reporter, and increasing amounts $(50,100,200$ and $400 \mathrm{ng})$ of NR0B1-pCDNA3.1/HA. The cells were treated with $10 \mathrm{nM}$ testosterone (T; Sigma-Aldrich) or ethanol vehicle for $24 \mathrm{~h}$ prior to performing the luciferase assay. Renilla and firefly luciferase activities were measured using the Dual-Luciferase reporter assay system. Firefly luciferase data were normalized to Renilla luciferase data. After normalization for transfection efficiency, the induction factors were calculated as ratios of the average value of the luciferase value of the T-stimulated samples vs. ethanol vehicle-treated samples.

Statistical analysis. All experiments were repeated at least three times. Statistical analysis was calculated using GraphPad Prism version 5.0 (GraphPad Software Inc., San Diego, CA, USA). The data values are expressed as the means \pm SD. The Student's t-test was used to compare the difference between two groups. A P-value $<0.05$ was considered to indicate a statistically significant difference.

\section{Results}

Expression of NROB1 in different mouse tissues. To assess the expression pattern of NR0B1 in adult mouse tissues, NR0B1 expression was examined in different mouse tissues using RT-qPCR and western blot analysis. The results showed that NrObl mRNA and its protein were highly expressed in the testes compared with that in the other tissues (Fig. 1). 
A

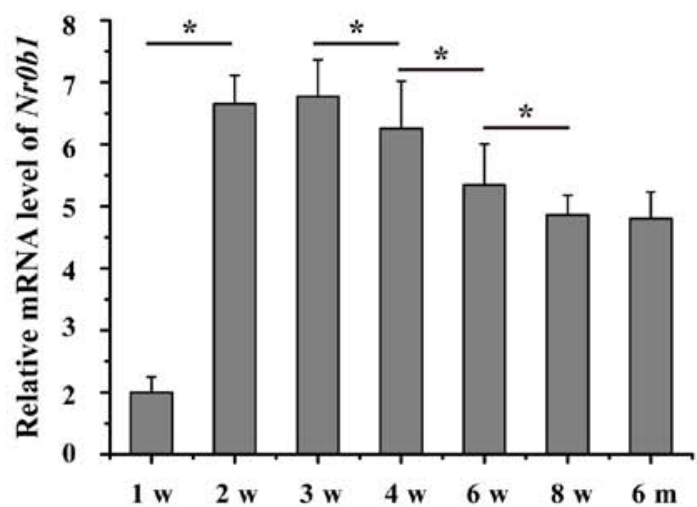

B

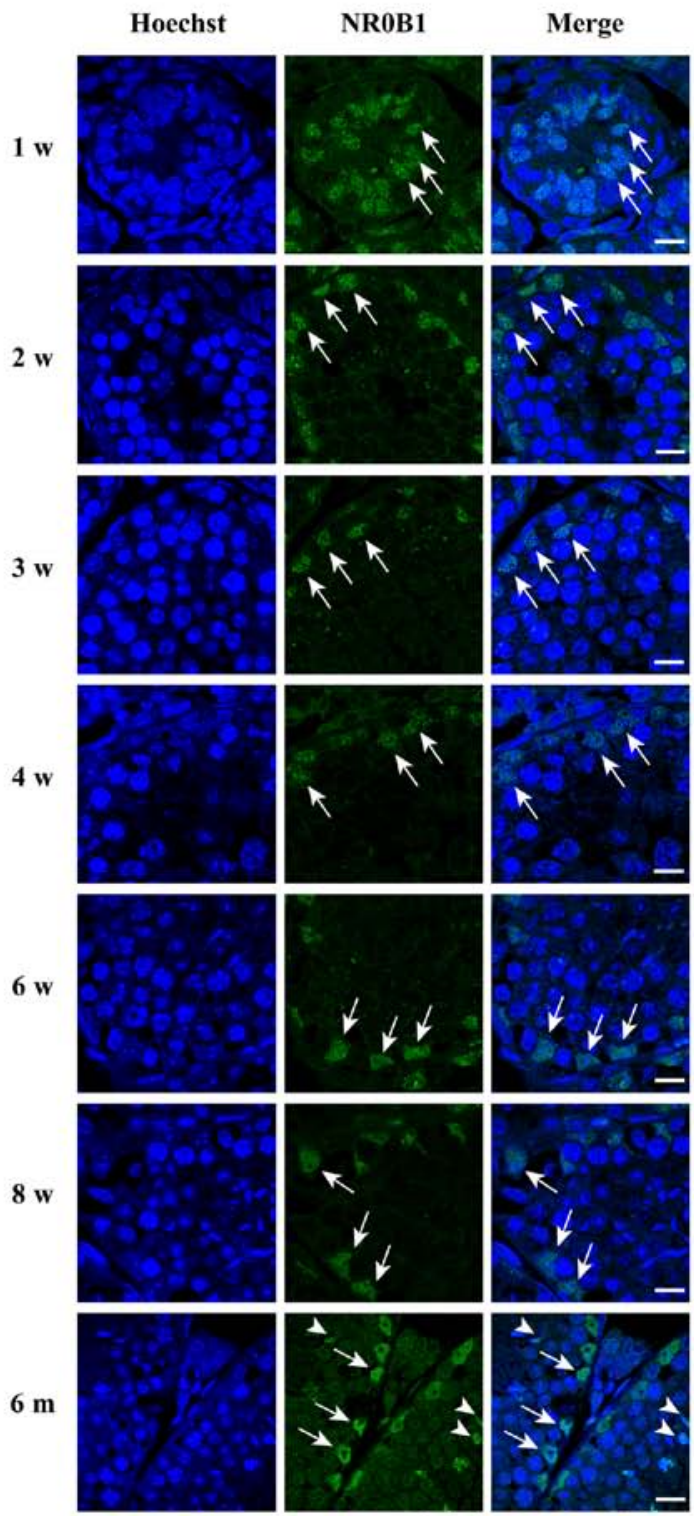

Figure 2. Age-dependent expression of NR0B1 in mouse testes. (A) The mRNA expression of $\mathrm{NrObl}$ in mouse testes at the indicated ages was determined by RT-qPCR. After normalizing to Gapdh, the relative expression of $\mathrm{NrObl}$ in testes at different ages was compared to that at week (w) 1. (B) The expression of NR0B1 at different developmental stages were examined by immunofluorescence analysis. The localization of NR0B1 was labeled with NR0B1 antibody (green). The cell nuclei were labeled with Hoechst 33258 (blue). Scale bar, $10 \mu \mathrm{m}$. White arrows indicate Sertoli cells (SCs) and the white arrowheads indicate spermatids. Data are expressed as the means \pm SD $(n=5)$, and the bars marked with asterisks indicate significant differences $(\mathrm{P}<0.05)$. We repeated each experiment three times by independent individuals. $\mathrm{m}$, month.
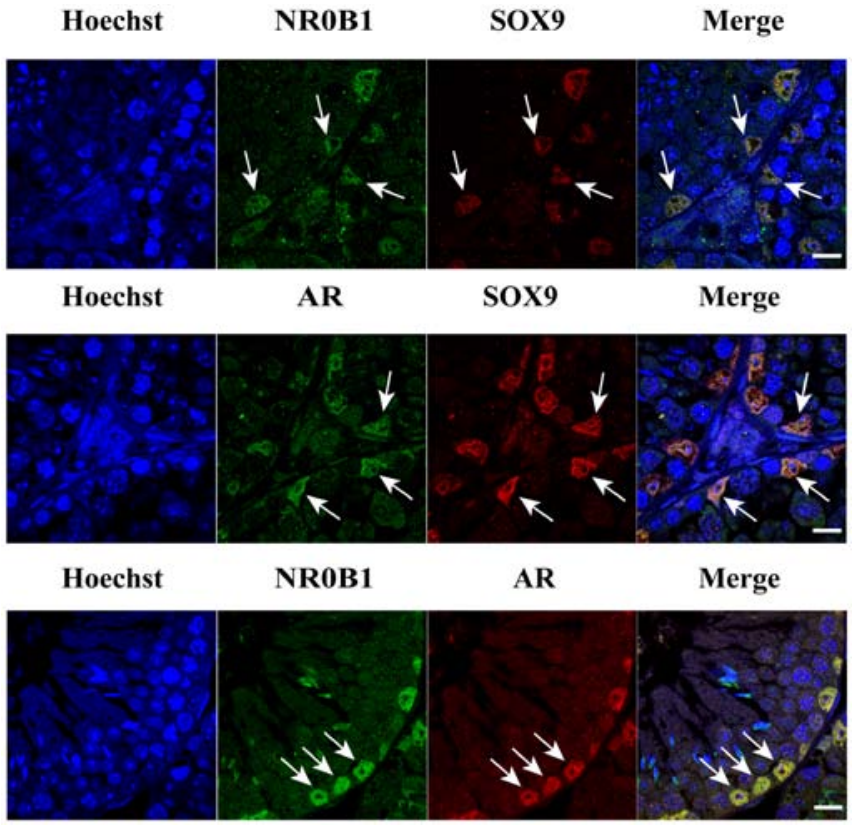

Figure 3. Co-location of NR0B1 and AR in mouse Sertoli cells (SCs) from 8-week-old adult mouse testes. The subcellular location of NR0B1 or androgen receptor (AR) was revealed with specific antibodies (green). SOX9 was used as a marker of SCs (red). Hoechst 33258 was used to stain the nuclei (blue). White arrows, SCs. Scale bar, $10 \mu \mathrm{m}$.

Temporal expression profile of NROB1 during mouse testicular development. To detect the expression of NR0B1 during testicular development, RT-qPCR and immunofluorescence analysis were performed. The results showed that NR0B1 was expressed in the testes during all the stages and decreased in a time-dependent manner from 2-8 weeks postnatally (Fig. 2A). As shown in Fig. 2B, NR0B1 was mainly located in the SCs at weeks 1-8, and was also expressed in the spermatids at 6 months.

Co-location of NROBI and AR in mouse SCs. Previous studies have established that NR0B1 expression is associated with testis cord development in mice $(19,20)$. To further test the hypothesis that AR function may be inhibited by NR0B1 expression, it was necessary to determine whether NR0B1 and AR were co-located in mouse SCs, as the AR is known to be expressed in developing mouse SCs (21-23). We next performed immunostaining of 8-week-old adult mouse testes. We observed that NR0B1 and AR were co-located in the mouse SCs (Fig. 3), as determined by co-immunostaining with a SC marker, SOX9.

$N R O B 1$ inhibits the effects of $A R$ on the expression of $A R$ target genes in an androgen-dependent manner. To determine whether NR0B1 is capable of inhibiting AR target gene expression, NR0B1-pCDNA3.1/HA and AR-pCDNA3.1 ${ }^{+}$ vectors were transfected into TM4 cells, following treatment with $10 \mathrm{nM}$ T for $24 \mathrm{~h}$. We determined-the expression of two AR target genes, ubiquitin-conjugating enzyme E2B (UBE2B) and heat shock transcription factor 1 (HSF1) using RT-qPCR and western blot analysis. The results showed that the overexpression of NR0B1 inhibited UBE2B expression and promoted HSF1 expression, while the knockdown of NR0B1 expression by siNr0b1 exerted opposite effects (Fig. 4), which indicated 
A

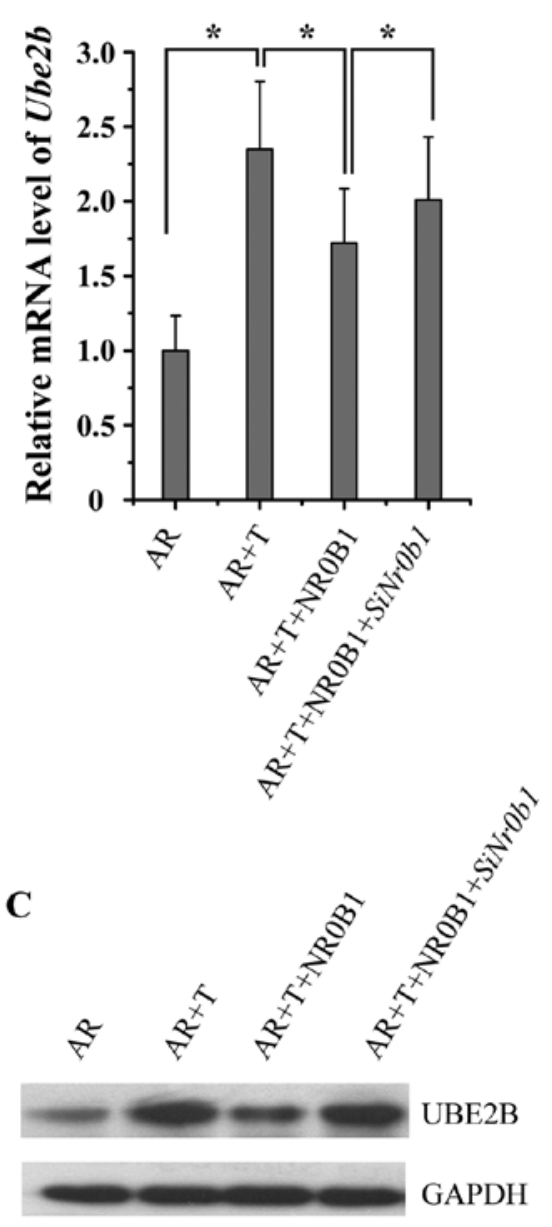

B

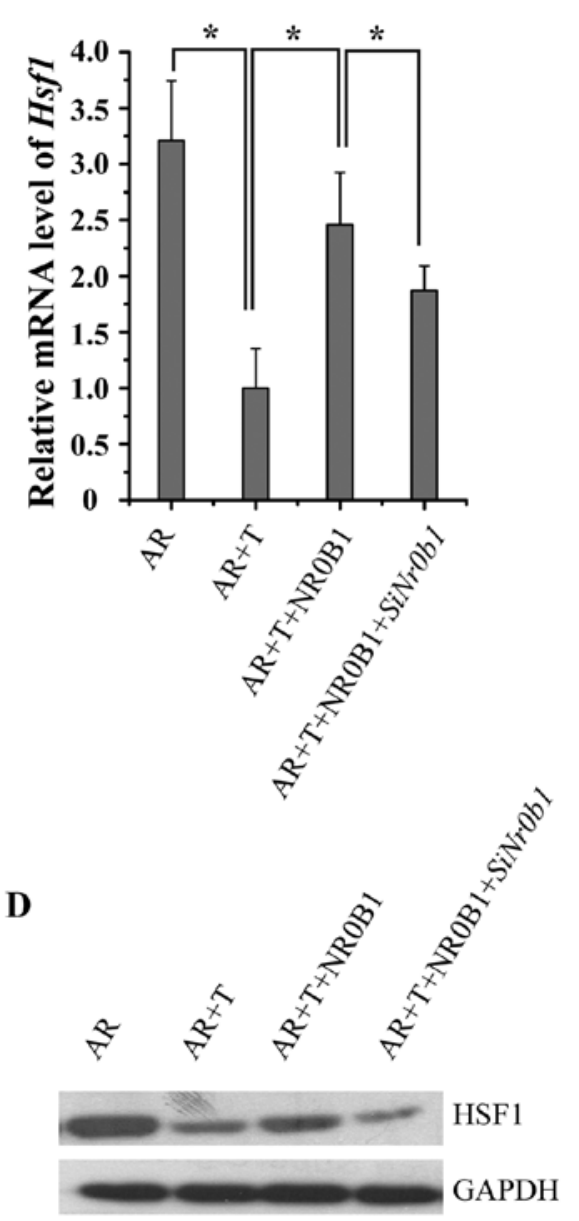

Figure 4. Inhibition of androgen receptor (AR) target genes by NR0B1 in an androgen-dependent manner. TM4 cells were transfected with AR- and NR0B1-overexpressing plasmids. Following treatment with $10 \mathrm{nM}$ testosterone (T) for $24 \mathrm{~h}$, the expression of ubiquitin-conjugating enzyme E2B (UBE2B) and heat shock transcription factor 1 (HSF1) in the TM4 cells was examined by (A and B) RT-qPCR and (C and D) western blot analysis. Data are expressed as the means $\pm \mathrm{SD}(\mathrm{n}=5)$, and bars marked with asterisks indicate significant differences $(\mathrm{P}<0.05)$. All experiments were performed three times by independent individuals. AR, only AR-overexpressing plasmid; AR+T, AR-overexpressing plasmid and T; AR+T+NR0B1, AR-overexpressing plasmid and T and NR0B1-overexpressing plasmid; AR+T+NR0B1+SiNr0b1, AR-overexpressing plasmid and T and NR0B1-overexpressing plasmid and siRNA-mediated knockdown NR0B1.

that NR0B1 reversed the effects of AR on the expression of its target gene.

NROBI inhibition of transcriptional AR activation. To determine whether NR0B1 inhibits the transcriptional activity of AR, we performed transient transfection studies using mouse SC lines (TM4 and 15P1). We used androgen-responsive luciferase reporter constructs, namely pMMTV-LUC containing mouse mammary tumor virus long terminal repeat (LTR), in which there are AREs in front of a TATA box. In the absence of NR0B1, AR activated pMMTV-LUC reporter in an agonistdependent fashion. The co-expression of increasing amounts of NR0B1 decreased AR activity in a dose-dependent manner, and $200 \mathrm{ng}$ NR0B1/well typically resulted in up to $70 \%$ inhibition of AR activity (Fig. 5A). Furthermore, NR0B1 did not directly inhibit the pMMTV-LUC reporter in the absence of AR. These results indicate that NR0B1 potently inhibited ligand-dependent transcriptional AR activation.

Transcriptional profiling studies with AR knockout mouse models searching for androgen-regulated genes relevant to spermatogenesis have identified many candidate target genes of ARs, including Rhox5, Gpx5, Lcn5, Tubb3, Crispl and Eppin (24-28). In our previous experiment, we have identified $U b e 2 b$ and $H s f 1$ as two critical target genes of the AR in mouse SCs. To further demonstrate that NR0B1 may inhibit the transcriptional activity of AR, we also performed transient transfection studies using TM4 and 15P1 cell lines. We used two other androgen-responsive luciferase reporter constructs, namely pUBE2B(-882/-343)-LUC and pHSF1(-625/-390)-LUC, containing an ARE in front of a TATA box $(29,30)$. In the absence of NR0B1, AR activated pUBE2B(-882/-343)-LUC reporter in an agonist-dependent fashion (Fig. 5B) and activated pHSF1(-625/-390)-LUC reporter in an antagonistdependent fashion (Fig. 5C). The co-expression of increasing amounts of NR0B1 decreased AR activity in a dose-dependent manner, and $200 \mathrm{ng}$ of NR0B1/well typically resulted in up to 55\% inhibition of the AR activity (Fig. 5B). Furthermore, NR0B1 did not directly inhibit pUBE2B(-882/-343)-LUC and pHSF1(-625/-390)-LUC reporters in the absence of AR. All of these results strongly suggest that NR0B1 antagonism plays a important role in modulating AR-dependent gene regulation in mouse SCs. 
A

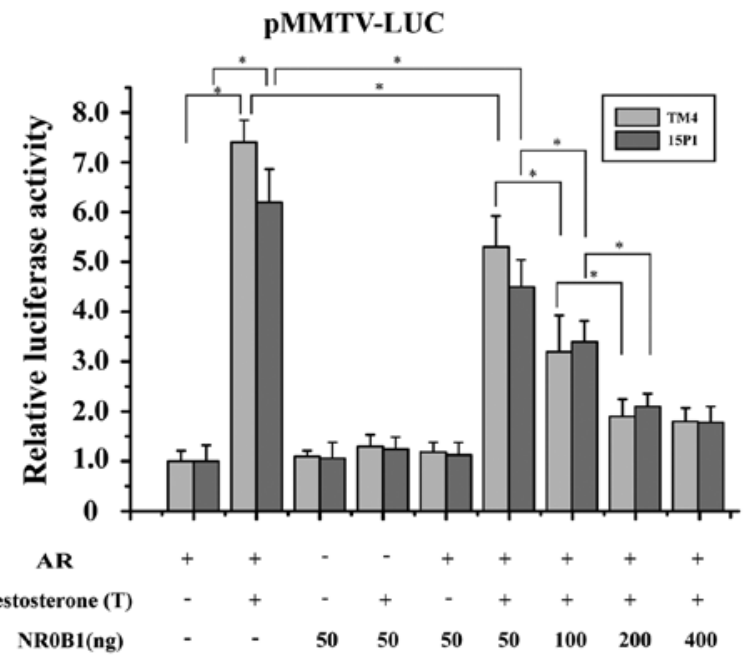

B

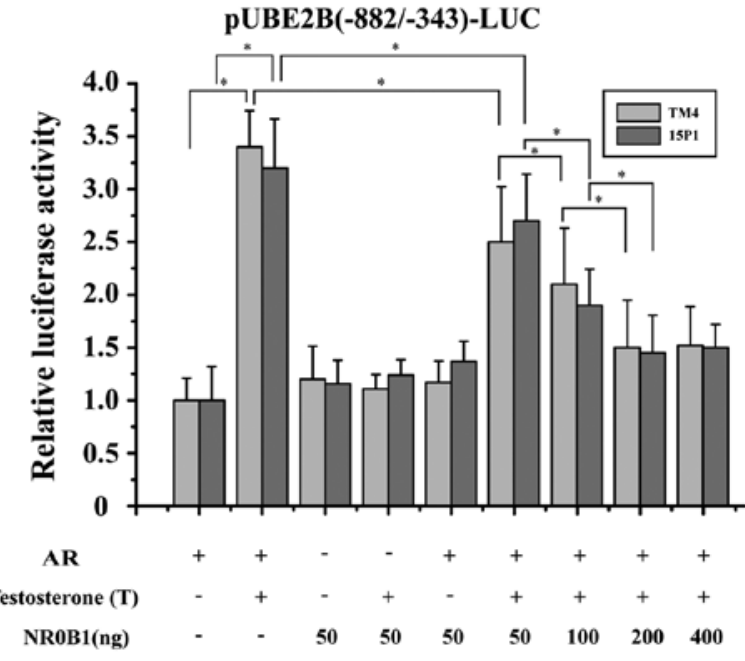

C

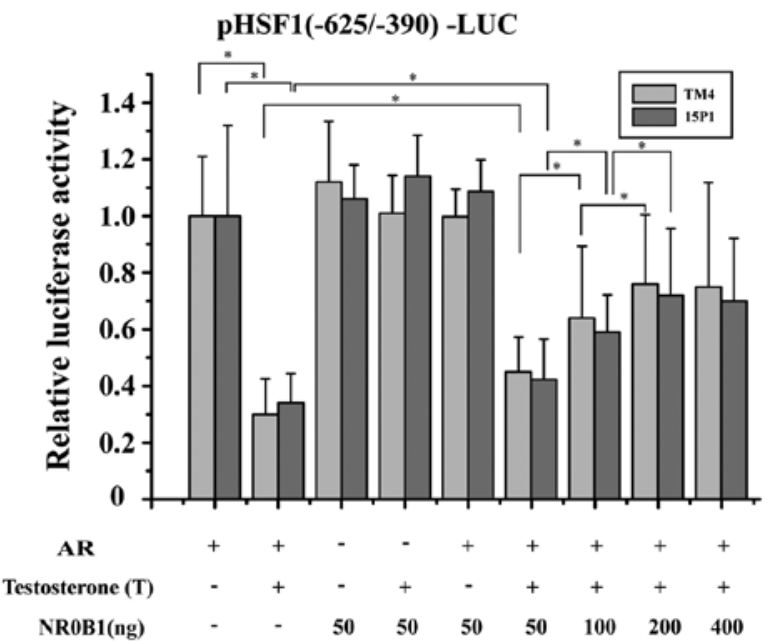

Figure 5. Inhibition of androgen receptor (AR)-dependent transcription by NR0B1 in mouse Sertoli cell lines. TM4 and 15P1 cells, cultured on 24-well plates, were transfected with $200 \mathrm{ng}$ AR-pCDNA3.1 ${ }^{+}$, $200 \mathrm{ng}$ pMMTV-LUC (A) or pUBE2B(-882/-343)-LUC (B) or pHSF1(-625/-390)-LUC (C) reporter, and increasing amounts $(50,100$, 200 and $400 \mathrm{ng}$ ) of NR0B1-pCDNA3.1/HA and treated with or without $10 \mathrm{nM}$ testosterone (T). Firefly luciferase data have been normalized to Renilla luciferase data. After normalization for transfection efficiency, induction factors were calculated as the ratios of the average value of the luciferase value of the T-stimulated samples vs. ethanol vehicle-treated samples. Data are expressed as the means \pm SD $(n=5)$, and bars marked with asterisks indicate significant differences $(\mathrm{P}<0.05)$.
A

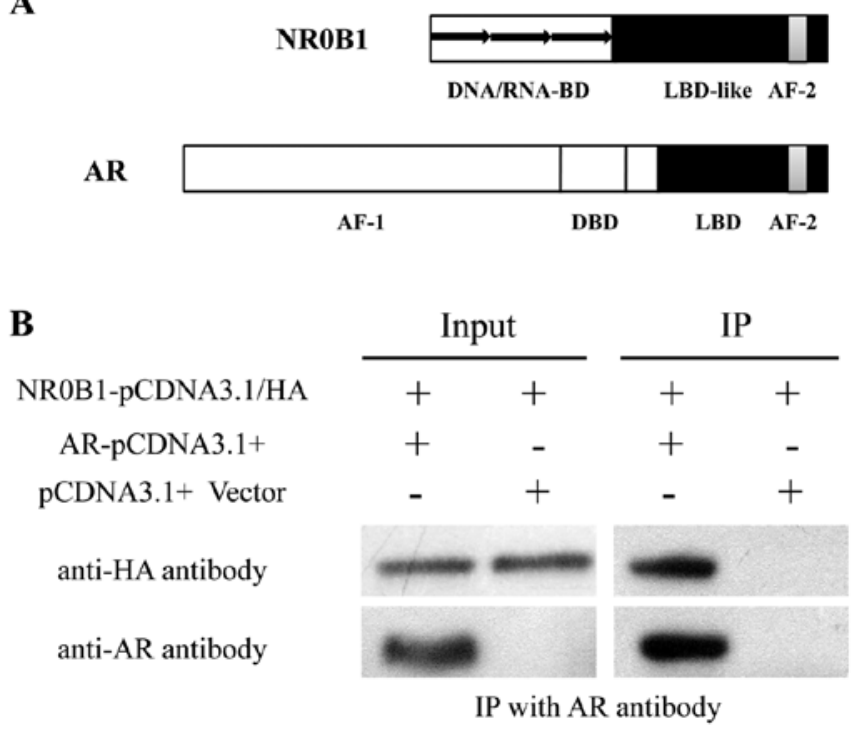

Figure 6. Interaction between NR0B1 and androgen receptor (AR) in vitro. (A) Schematic representation of the NR0B1 and AR domain structure. (B) NR0B1-pCDNA3.1/HA was transfected into 293T cells together with AR-pCDNA3.1 $1^{+}$or the vector control. NR0B1 was immunoprecipitated using an anti-AR antibody. Anti-HA antibody (upper panel) or anti-AR antibody (lower panel) were used for western blot analysis. Expression of NR0B1-pCDNA3.1/ HA and AR-pCDNA3.1 ${ }^{+}$in 293 T cells was indicated in the lanes labeled 'Input'. The immunoprecipitation products indicated that NR0B1-pCDNA3.1/ HA was pulled down in the presence only of AR-pCDNA3.1 ${ }^{+}$but not the vector control. DBD, DNA-binding domain; LBD, ligand-binding domain.

Interaction of $\mathrm{NROB1}$ and AR in vitro. $\mathrm{NrObl}$ has been classified as an orphan member of the nuclear receptor superfamily $(31,32)$. The NR0B1 domain structure has an amino-terminal domain (DNA/RNA-BD), a carboxy-terminal domain (LBD-like) and an AF-2 transactivation domain (Fig. 6A). The amino-terminal domain has a novel structure consisting of 3.5 alanine/glycinerich repeats of a 65-70 amino acid motif that has no known homology to any other proteins, with the exception of the related nuclear receptor superfamily member, small heterodimer partner (SHP), encoded by NR0B2 (33). ARs (also known as dihydrotestosterone receptors) are nuclear hormone receptors of the NR3C class. The AR domain structure has a AF-1 transactivation domain, a DBD, a LBD and an AF-2 transactivation domain (Fig. 6A).

In our previous experiment, we found that NR0B1 inhibits the transcriptional activation of AR, and NR0B1 and AR were co-located in mouse SCs. From these results, we speculated that NR0B1 interacts with AR and then inhibits its transcriptional activation. The interaction between NR0B1 and AR was determined using an in vitro co-immunoprecipitation assay. The AR and HA-fused NR0B1 vectors were transcribed as described above and transfected into 293T cells. We found that HA-fused NR0B1 protein was pulled down by anti-AR antibody, which demonstrated that NR0B1 interacted with AR in mouse SCs (Fig. 6B).

\section{Discussion}

$\mathrm{NrObl}$ is an atypical member of the nuclear receptor superfamily that is predominantly expressed in mouse testes. In a previous study aiming to evaluate the role of $\mathrm{NrObl}$ in mice, 
NrObl was expressed by the Müllerian-inhibiting substance promoter (MIS-NrObl) in the genetic background of the

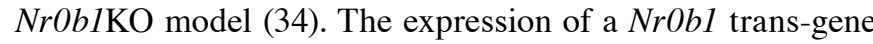
was sufficient to partially rescue the primary testicular defect of the male NrObl-deficient (KO) mouse. Even so, the function of $\mathrm{NrObl}$ in mouse SCs remains unclear.

Androgen signaling via the AR may be represented as a multistep cascade involving the dissociation of cytoplasmic chaperone/heat shock protein complexes upon ligand-binding, nuclear localization, DNA binding, and the association of the AR with various bona fide co-activators, such as histone acetyltransferases [p160s, cAMP response element binding protein (CREB)-binding protein (CBP), p300, p300/CBP-associated factor (PCAF), Tat-interacting protein 60 (TIP60)] and a number of unrelated proteins, including protein inhibitor of activated STAT (PIAS) proteins (35), AR-interacting protein (ARIP)/small nuclear ring finger protein (SNURF)/RNF4s, and AR-interacting nuclear protein kinase (ANPK) (17). Considerably less is known about the mechanisms by which androgen-dependent transcription is inhibited, and candidate co-repressors have only recently been identified. They include the amino-terminal enhancer of split, a member of the Groucho/transducin-like enhancer of split family of co-repressors, that is not associated with histone deacetylases, but instead functions through direct contact with the basal transcription factor, TFIIE (36). Other repressors of androgen action include cyclin D1, which directly antagonizes the acetyltransferase, PCAF (37); SMAD3, an intracellular mediator of the TGF- $\beta$ pathway (38); and the protein kinases, PAK6 and AKT, which presumably repress AR activity through direct phosphorylation $(39,40)$. Moreover, a novel covalent modification of the AR by the attachment of small ubiquitinrelated modifier 1 in certain contexts inhibits the transcriptional activity of the AR (41).

In this study, we have demonstrated that NR0B1 interacts with $A R$ and inhibits the transcriptional activation of $A R$ in mouse SCs. The enforced expression of NR0B1 suppresses the expression of target genes of AR, while the silencing of NR0B1 promotes the expression of these target genes. This is consistent with our observation that a significant amount of NR0B1 co-localized with AR in the nuclei of mouse SCs. Although the precise mechanisms responsible for these phenomena remain unclear, NR0B1 most likely interferes with the events required for AR activation in mouse SCs. This may include interference with the association and dissociation of chaperones or interference with nuclear import by masking the nuclear localization signals of AR. In support of the general application of this mechanism, there is preliminary evidence from several studies demonstrating that NR0B1 is also able to repress steroidogenic factor 1 (SF-1) and estrogen receptor (ER)-mediated transactivation (42-45).

AR function is often altered in humans with reproductive abnormalities, as well as in prostate cancer, due to mutations within the LBD $(15,46)$. While some of these mutations have been demonstrated to affect the ligand-binding capacity and specificity, others are proposed to affect inter-domain communication or direct interactions with co-activators (47-49). Similarly, multiple $N R O B 1$ mutations have been detected that primarily target the putative LBD of NROB1 (50-52). One of these mutations (NROB1 R267P) has been found to be less potent in ER inhibition (42). However, as this mutation presumably affects several features of the $N R O B 1 \mathrm{LBD}$, further investigations are required in order to determine whether mutated $N R O B I$ displays changes with respect to intracellular tethering, co-activator competition or co-repressor recruitment. AR and NR0B1 are the only two reproductive nuclear receptors in which high numbers of natural mutations have been detected in human males (53). Notably, the genes for both $A R$ and NROBI are located on the X-chromosome. Thus, all mutations affecting the function yield a phenotype. Interactions between NR0B1 and AR may be important for the proper development of the male reproductive system.

In conclusion, we have identified NR0B1 as a new AR co-repressor in mouse SCs. We have provided evidence, for the first time to the best of our knowledge, for the novel roles of NR0B1 as an inhibitory co-regulator of the AR in mouse SCs. These data strongly suggest that NR0B1 antagonism plays a important role in modulating AR-dependent gene regulation in the male reproductive system.

\section{Acknowledgements}

The present study was supported by grants from the National Natural Science Foundation of China (nos. 31271244 and 31471344) and the Shenzhen Project of Science and Technology (nos. XB201104220045A and JCYJ20140415162543017). We would also like to thank Dr Qiaoxia Zhang for kindly supplying the AR overexpression plasmid, and Dr Lisha Mou, Shenzhen Key Laboratory of Genitourinary Tumor, Shenzhen Second People's Hospital, First Affiliated Hospital of Shenzhen University for kindly supplying the reporter plasmids, pMMTV-LUC, pUBE2B(-882/-343)-LUC and pHSF1(-625/-390)-LUC.

\section{References}

1. Goto M and Katsumata N: X-linked adrenal hypoplasia congenita caused by a novel intronic mutation of the $D A X-1$ gene. Horm Res 71: 120-124, 2009.

2. Ikeda Y, Takeda Y, Shikayama T, Mukai T, Hisano S and Morohashi KI:Comparative localization ofDax-1 and Ad4BP/SF-1 during development of the hypothalamic-pituitary-gonadal axis suggests their closely related and distinct functions. Dev Dyn 220: 363-376, 2001.

3. Bardoni B, Zanaria E, Guioli S, Floridia G, Worley KC, Tonini G, Ferrante E, Chiumello G, McCabe ER, Fraccaro M, et al: A dosage sensitive locus at chromosome Xp21 is involved in male to female sex reversal. Nat Genet 7: 497-501, 1994.

4. Achermann JC, Meeks JJ and Jameson JL: Phenotypic spectrum of mutations in DAX-1 and SF-1. Mol Cell Endocrinol 185: 17-25, 2001.

5. Yu RN, Ito M, Saunders TL, Camper SA and Jameson JL: Role of Ahch in gonadal development and gametogenesis. Nat Genet 20: 353-357, 1998.

6. Jeffs B, Meeks JJ, Ito M, Martinson FA, Matzuk MM, Jameson JL and Russell LD: Blockage of the rete testis and efferent ductules by ectopic Sertoli and Leydig cells causes infertility in Daxl-deficient male mice. Endocrinology 142: 4486-4495, 2001.

7. Heemers HV and Tindall DJ: Androgen receptor (AR) coregulators: a diversity of functions converging on and regulating the AR transcriptional complex. Endocr Rev 28: 778-808, 2007.

8. Heinlein CA and Chang C: Androgen receptor (AR) coregulators: an overview. Endocr Rev 23: 175-200, 2002.

9. Patrão MT, Silva EJ and Avellar MC: Androgens and the male reproductive tract: an overview of classical roles and current perspectives. Arq Bras Endocrinol Metabol 53: 934-945, 2009.

10. De Gendt K, Swinnen JV, Saunders PT, Schoonjans L, Dewerchin M, Devos A, Tan K, Atanassova N, Claessens F, Lécureuil C, et al: A Sertoli cell-selective knockout of the androgen receptor causes spermatogenic arrest in meiosis. Proc Natl Acad Sci USA 101: 1327-1332, 2004. 
11. Wang RS, Yeh S, Tzeng CR and Chang C: Androgen receptor roles in spermatogenesis and fertility: lessons from testicular cell-specific androgen receptor knockout mice. Endocr Rev 30: 119-132, 2009

12. Yeh S, Tsai MY, Xu Q, Mu XM, Lardy H, Huang KE, Lin H, Yeh SD, Altuwaijri S, Zhou X, et al: Generation and characterization of androgen receptor knockout (ARKO) mice: an in vivo model for the study of androgen functions in selective tissues. Proc Natl Acad Sci USA 99: 13498-13503, 2002.

13. Quigley CA,De Bellis A, Marschke KB, el-Awady MK, Wilson EM and French FS: Androgen receptor defects: historical, clinical, and molecular perspectives. Endocr Rev 16: 271-321, 1995.

14. Yong EL, Ghadessy F, Wang Q, Mifsud A and Ng SC: Androgen receptor transactivation domain and control of spermatogenesis. Rev Reprod 3: 141-144, 1998

15. Culig Z, Hobisch A, Bartsch G and Klocker H: Androgen receptor - an update of mechanisms of action in prostate cancer. Urol Res 28: 211-219, 2000

16. Hughes IA: Minireview: sex differentiation. Endocrinology 142 3281-3287, 2001

17. Jänne OA, Moilanen AM, Poukka H, Rouleau N, Karvonen U, Kotaja N, Häkli M and Palvimo JJ: Androgen-receptor-interacting nuclear proteins. Biochem Soc Trans 28: 401-405, 2000.

18. Schmittgen TD and Livak KJ: Analyzing real-time PCR data by the comparative C(T) method. Nat Protoc 3: 1101-1108, 2008.

19. Meeks JJ, Crawford SE, Russell TA, Morohashi K, Weiss J and Jameson JL: Dax1 regulates testis cord organization during gonadal differentiation. Development 130: 1029-1036, 2003.

20. Hanley NA, Hagan DM, Clement-Jones M, Ball SG, Strachan T, Salas-Cortés L, McElreavey K, Lindsay S, Robson S, Bullen P, et al: SRY, SOX9, and DAX1 expression patterns during human sex determination and gonadal development. Mech Dev 91: 403-407, 2000.

21. Münsterberg A and Lovell-Badge R: Expression of the mouse anti-müllerian hormone gene suggests a role in both male and female sexual differentiation. Development 113: 613-624, 1991.

22. Kent J, Wheatley SC, Andrews JE, Sinclair AH and Koopman P: A male-specific role for $S O X 9$ in vertebrate sex determination. Development 122: 2813-2822, 1996.

23. Morais da Silva S, Hacker A, Harley V, Goodfellow P, Swain A and Lovell-Badge R: Sox9 expression during gonadal development implies a conserved role for the gene in testis differentiation in mammals and birds. Nat Genet 14: 62-68, 1996.

24. Denolet E, De Gendt K, Allemeersch J, Engelen K, Marchal K, Van Hummelen P, Tan KA, Sharpe RM, Saunders PT, Swinnen JV and Verhoeven G: The effect of a Sertoli cell-selective knockout of the androgen receptor on testicular gene expression in prepubertal mice. Mol Endocrinol 20: 321-334, 2006.

25. De Gendt K, Denolet E, Willems A, Daniels VW, Clinckemalie L, Denayer S, Wilkinson MF, Claessens F, Swinnen JV and Verhoeven G: Expression of Tubb3, a beta-tubulin isotype is regulated by androgens in mouse and rat Sertoli cells. Biol Reprod 85: 934-945, 2011.

26. Zhou W, Wang G, Small CL, Liu Z, Weng CC, Yang L, Griswold MD and Meistrich ML: Gene expression alterations by conditional knockout of androgen receptor in adult Sertoli cells of Utp14b jsd/jsd (jsd) mice. Biol Reprod 84: 400-408, 2011

27. Zhang QX, Zhang XY, Zhang ZM, Lu W, Liu L, Li G, Cai ZM, Gui YT and Chang C: Identification of testosterone-/androgen receptor-regulated genes in mouse Sertoli cells. Asian J Androl 14: 294-300, 2012.

28. Eacker SM, Shima JE, Connolly CM, Sharma M, Holdcraft RW, Griswold MD and Braun RE: Transcriptional profiling of androgen receptor (AR) mutants suggests instructive and permissive roles of AR signaling in germ cell development. Mol Endocrinol 21: 895-907, 2007.

29. Yang L, Wang Y, Zhang Q, Lai Y, Li C, Zhang Q, Huang W, Duan Y, Jiang Z, Li X, et al: Identification of Hsf1 as a novel androgen receptor-regulated gene in mouse Sertoli cells. Mol Reprod Dev 81: 514-523, 2014.

30. Mou L, Zhang Q, Wang Y, Zhang Q, Sun L, Li C, Huang W, Yuan Y, Duan Y, Diao R, et al: Identification of Ube2b as a novel target of androgen receptor in mouse sertoli cells. Biol Reprod 89: 32, 2013.

31. Burris TP, Guo W and McCabe ER: The gene responsible for adrenal hypoplasia congenita, DAX-1, encodes a nuclear hormone receptor that defines a new class within the superfamily. Recent Prog Horm Res 51: 241-260, 1996.
32. Giguère V: Orphan nuclear receptors: from gene to function Endocr Rev 20: 689-725, 1999.

33. Iyer AK and McCabe ER: Molecular mechanisms of DAX action. Mol Genet Metab 83: 60-73, 2004.

34. Jeffs B, Ito M, Yu RN, Martinson FA, Wang ZJ, Doglio LT and Jameson JL: Sertoli cell-specific rescue of fertility, but not testicular pathology, in Daxl (Ahch)-deficient male mice. Endocrinology 142: 2481-2488, 2001.

35. Kotaja N, Vihinen M, Palvimo JJ and Jänne OA: Androgen receptor-interacting protein 3 and other PIAS proteins cooperate with glucocorticoid receptor-interacting protein 1 in steroid receptor-dependent signaling. J Biol Chem 277: 17781-17788, 2002.

36. Yu X, Li P, Roeder RG and Wang Z: Inhibition of androgen receptor-mediated transcription by amino-terminal enhancer of split. Mol Cell Biol 21: 4614-4625, 2001.

37. Reutens AT, Fu M, Wang C, Albanese C, McPhaul MJ, Sun Z, Balk SP, Jänne OA, Palvimo JJ and Pestell RG: Cyclin D1 binds the androgen receptor and regulates hormone-dependent signaling in a p300/CBP-associated factor (P/CAF)-dependent manner. Mol Endocrinol 15: 797-811, 2001.

38. Hayes SA, Zarnegar M, Sharma M, Yang F, Peehl DM, ten Dijke P and Sun Z: SMAD3 represses androgen receptor-mediated transcription. Cancer Res 61: 2112-2118, 2001.

39. Lin HK, Yeh S, Kang HY and Chang C: Akt suppresses androgen-induced apoptosis by phosphorylating and inhibiting androgen receptor. Proc Natl Acad Sci USA 98: 7200-7205, 2001.

40. Yang F,Li X, Sharma M,Zarnegar M,Lim B and Sun Z: Androgen receptor specifically interacts with a novel p21-activated kinase, PAK6. J Biol Chem 276: 15345-15353, 2001.

41. Poukka H, Karvonen U, Janne OA and Palvimo JJ: Covalent modification of the androgen receptor by small ubiquitin-like modifier 1 (SUMO-1). Proc Natl Acad Sci USA 97: 14145-14150, 2000.

42. Zhang H, Thomsen JS, Johansson L, Gustafsson JA and Treuter E: DAX-1 functions as an LXXLL-containing corepressor for activated estrogen receptors. J Biol Chem 275: 39855-39859, 2000

43. Ito M, Yu R and Jameson JL: DAX-1 inhibits SF-1-mediated transactivation via a carboxy-terminal domain that is deleted in adrenal hypoplasia congenita. Mol Cell Biol 17: 1476-1483, 1997.

44. Altincicek B, Tenbaum SP, Dressel U, Thormeyer D, Renkawitz R and Baniahmad A: Interaction of the corepressor Alien with DAX-1 is abrogated by mutations of DAX-1 involved in adrenal hypoplasia congenita. J Biol Chem 275: 7662-7667, 2000.

45. Crawford PA, Dorn C, Sadovsky Y and Milbrandt J: Nuclear receptor DAX-1 recruits nuclear receptor corepressor N-CoR to steroidogenic factor 1. Mol Cell Biol 18: 2949-2956, 1998.

46. Yong EL, Lim J, Qi W, Ong V and Mifsud A: Molecular basis of androgen receptor diseases. Ann Med 32: 15-22, 2000

47. Thompson J, Saatcioglu F, Jänne OA and Palvimo JJ: Disrupted amino- and carboxyl-terminal interactions of the androgen receptor are linked to androgen insensitivity. Mol Endocrinol 15: 923-935, 2001.

48. Beilin J, Ball EM, Favaloro JM and Zajac JD: Effect of the androgen receptor CAG repeat polymorphism on transcriptional activity: Specificity in prostate and non-prostate cell lines. J Mol Endocrinol 25: 85-96, 2000.

49. Slagsvold T, Kraus I, Bentzen T, Palvimo J and Saatcioglu F: Mutational analysis of the androgen receptor AF-2 (activation function 2) core domain reveals functional and mechanistic differences of conserved residues compared with other nuclear receptors. Mol Endocrinol 14: 1603-1617, 2000.

50. Reutens AT, Achermann JC, Ito M, Ito M, Gu WX, Habiby RL, Donohoue PA, Pang S, Hindmarsh PC and Jameson JL: Clinical and functional effects of mutations in the $D A X-1$ gene in patients with adrenal hypoplasia congenita. J Clin Endocrinol Metab 84: 504-511, 1999.

51. Muscatelli F, Strom TM, Walker AP, Zanaria E, Récan D, Meindl A, Bardoni B, Guioli S, Zehetner G, Rabl W, et al: Mutations in the $D A X-1$ gene give rise to both X-linked adrenal hypoplasia congenita and hypogonadotropic hypogonadism. Nature 372: 672-676, 1994

52. Lalli E, Bardoni B, Zazopoulos E, Wurtz JM, Strom TM, Moras D and Sassone-Corsi P: A transcriptional silencing domain in DAX-1 whose mutation causes adrenal hypoplasia congenita. Mol Endocrinol 11: 1950-1960, 1997.

53. Achermann JC and Jameson JL: Fertility and infertility: genetic contributions from the hypothalamic-pituitary-gonadal axis. Mol Endocrinol 13: 812-818, 1999. 